\title{
The determinants of aggression in male Siamese fighting fish, Betta splendens
}

\author{
R. E. McGoran ${ }^{a^{*}}$, S. K. Papworth ${ }^{a} \&$ S. J. Portugal ${ }^{a}$ \\ ${ }^{a}$ School of Biological Sciences, Royal Holloway University of London, Egham, Surrey, UK \\ TW20 OEX
}

* Corresponding author: Rebecca.Mcgoran.2012@live.rhul.ac.uk 


\section{ABSTRACT}

2 Siamese fighting fish, Betta splendens, have been extensively studied due to their aggression 3 and stereotypical displays. Many studies have focused on their characteristic opercular 4 flaring, while the less aggressive and less energetically costly lateral display have been 5 comparatively understudied. Many factors have been shown to influence aggression in

6 Bettas, notably body length and the personality trait of boldness, however, the role that colour 7 plays in determining an individual's aggressiveness is much less clear. The role of colour has 8 only been briefly studied, and based on human interpretations of colour, i.e. limited to what 9 the receivers' eyes and sensory systems actually can process and discriminate, with results 10 suggesting blue males are more aggressive than red males. Using male-male interactions, 11 measuring opercular flaring and lateral display we found that colour and personality do play a 12 role in determining the degree of aggressiveness in Betta splendens. Blue-finned males were 13 more aggressive, performing longer lateral displays more frequently. Blue fins are a 14 phenotype observed in wild type males and is likely selected for to allow visual cues to travel 15 through the murky water they inhabit. Body mass was positively correlated with lateral 16 display frequency, and opercular flare frequency and duration. Finally, neophobic individuals 17 - individuals that were less willing to approach a novel object - were more aggressive, 18 performing significantly more lateral displays. This indicates that personality may impact 19 fighting strategy, with males either choosing to end conflicts quickly with more aggressive 20 displays or to outlast their opponent with less energetically costly displays.

22 Key words: Behaviour; Boldness; Male-male displays; Neophobia; Spectrophotometry; 23 Territoriality

\section{INTRODUCTION}

Animals compete aggressively with individuals of the same species over limited resources, such as territory and mates (Parker 1974). Individuals perform displays to settle disputes for resources, conveying information about their physiological condition, and their willingness to fight (Parker 1974). Successful displays can increase access to mates, mating success and territory size (Alton et al. 2013). Siamese fighting fish (Betta splendens) are an

32 extreme example of an aggressive species. B. splendens are a facultatively air-breathing 33 freshwater Anabantoid fish, which inhabit hypoxic waters where air-breathing is essential 34 (Graham 1997). Domestic breeds have long been considered model organisms for 
35 behavioural studies due to their aggression, and stereotypic and conspicuous displays (Tate et 36 al. 2017). Male B. splendens have multiple visual displays, including fin flaring and opercular 37 flaring, which are designed to intimidate opponents by increasing their perceived body size 38 (Simpson 1968). Examining social interactions in B. splendens has suggested that opercular 39 flaring (raising of the operculae) and lateral displays (fin flaring while showing their 40 broadside) are the most common aggressive displays in male-male and male-female 41 interactions (Forsatkar et al. 2016). Displays often start with low-level aggressive behaviours, 42 i.e. fin flaring, which can develop into more aggressive actions, i.e. opercular flaring and 43 biting (Forsatkar et al. 2016). The duration of opercular flaring relates to an individual's 44 condition and has been demonstrated to be a reliable predictor of the winner of a male-male 45 aggressive interaction (Simpson 1968).

Historically, much focus has been on opercular flare duration as an indicator of aggression (Tate et al. 2017). This study aims to explore what characteristics relate to an

49 individual's aggression by studying morphological and behavioural traits. Several 50 characteristics have been linked to aggression in B. splendens including boldness (Hebert et 51 al. 2014), colour (Simpson 1968) and size (Jaroensutasinee and Jaroensutasinee 2001). 52 Subsequently, this study predicts that aggressive male B. splendens will display bolder 53 personality traits (greater exploration and less neophobic in a novel environment), coupled 54 with a larger body size. The threat displays of B. splendens are highly visual, thus it is likely 55 colour contributes to aggression (Simpson 1968). Studies investigating the role of colour in 56 animal behaviour have typically relied on categorical human assessments of colour, which 57 are likely to underestimate or miscategorise the true colour of an individual. Therefore, using 58 spectrophotometry, we determined the true colour of individual B. splendens and predict that 59 those reflecting a shorter wavelength will be more aggressive.

\section{METHODS}

\section{Subjects and housing}

63 Adult male B. splendens $(\mathrm{N}=19)$ were housed individually in visually isolated $10.5 \mathrm{x}$ $6428 \times 16.5 \mathrm{~cm}$ tanks and kept in laboratory conditions (light:dark cycle $14: 10 \mathrm{~h}, 25 \pm 1^{\circ} \mathrm{C}, 7.8-$ $658.2 \mathrm{pH}$ ). Males were kept in isolation in their home tanks for at least 7 days prior to the 66 behavioural observations to reduce the effects of prior social experience on their responses. 67 Individuals were fed once a day, six days a week, on a mix of Daphnia spp., Artemia spp. and 
68 Tetra ${ }^{\mathrm{TM}}$ Betta flake food. The males were wet weighed to record their body mass $(\mathrm{g})$ and their

69 body and fin colour were recorded using spectrophotometry (see supplementary material for

70 full methods).

\section{General experimental set-up}

73 For all experiments, the tanks contained tap water $(\mathrm{pH} 7.4)$ aged for at least $18 \mathrm{~h}$ 74 overnight at a temperature of $24.9 \pm 0.96^{\circ} \mathrm{C}$. Due to a limited supply of water from the home 75 tank system aged tap water was used. All tanks were covered to remove external stimuli, 76 except in the aggression trial where the front was left uncovered for observations. All 77 behaviour was recorded using the PC event-recording software, Stopwatch+.

\section{Aggression}

Randomly selected males were placed in two separate tanks $(35 \times 18 \times 23.5 \mathrm{~cm})$

81 placed together lengthwise with opaque paper preventing opponent observations. Males were 82 given an hour to acclimatise before the partition was removed and their behaviour was 83 recorded for 20 minutes. The following behaviours were recorded: (a) the duration $\left(\mathrm{O}_{\mathrm{d}}\right)$ and 84 frequency $\left(\mathrm{O}_{\mathrm{f}}\right)$ of opercular flaring, (b) the duration $\left(\mathrm{L}_{\mathrm{d}}\right)$ and frequency $\left(\mathrm{L}_{\mathrm{f}}\right)$ of lateral 85 displays. Each individual was observed once per day and repeat encounters were allowed to 86 occur. Males met each opponent between 1 and 5 times. Male aggression was assessed using 87 David's score (DS, Gammell et al. 2003).

\section{Boldness}

89 Boldness trials were performed in a $48 \times 33 \times 11 \mathrm{~cm}$ tank divided into thirds: a 90 sheltered (containing a cave, plastic weeds and a plastic cover to create shade), intermediate 91 (containing plastic weeds) and exposed zone (well-lit empty and shallow section with a 92 predator silhouette hanging above). A randomly selected male was placed into the sheltered 93 end and held in place by a Perspex screen. The fish were given five minutes to acclimatise 94 before the screen was removed and the time spent in each section was recorded for 20 95 minutes. Individuals were tested once a week for three weeks. A boldness score was 96 generated by weighting each section of the tank (see Portugal et al. 2017a). The sheltered, 97 intermediate and exposed zones were weighted as one, two and three times the total length of

98 time an individual spent in each respectively. The scores were averaged over three repeats.

\section{Neophobia}


100 Neophobia trials were performed in the aggression tanks, which fish were already 101 highly accustomed too, so that only introduced novel objects would influence behaviour. The 102 tank was split into thirds. A novel object was placed in one end. The experimental design was 103 identical to the boldness trials with regards to repeats, recording and weighting of the three 104 zones. A different novel object was used for each trial.

\section{Statistical analysis}

106 Repeatability values were calculated using a one-way ANOVA for boldness and 107 neophobia, providing a measure of individual consistency. Spearman's correlation was 108 calculated between the repeatable boldness and neophobia traits for signs of any behaviours measuring the same trait. Any significantly correlated traits were reduced to the most

110 repeatable measure. Linear models were performed to determine which variable related to 111 aggression. All analysis was performed using R, version 3.3.1 (R Development Core Team, 112 2013).

\section{RESULTS}

\section{Boldness and neophobia}

116 Individual boldness was not consistent across trials (bold score: $R=-0.05, P=0.64$; 117 latency to leave the sheltered zone: $R=0.007, P=0.46$; latency to enter the exposed zone: $R$ $118<0.001, P=0.48$ ). However, individual neophobia was repeatable across trials (neophobia 119 score: $R=0.45, P<0.001$; latency to enter the novel object zone: $R=0.47, P<0.001)$. Both 120 neophobia measures were significantly correlated (Spearman's rank correlation: $r=-0.835, N$ $121=19, P<0.001$ ), hence, the latency to enter the novel object zone was used in the linear 122 model.

\section{Colour}

125 Average fin colour of the Bettas ranged from 482.7 to $608.5 \mathrm{~nm}$, while the average 126 body colour ranged from 472.9 to $604.8 \mathrm{~nm}$. The visible light spectrum includes: violet (400$127450 \mathrm{~nm})$, blue $(450-500 \mathrm{~nm})$, green $(500-570 \mathrm{~nm})$, yellow $(570-590 \mathrm{~nm})$, orange (590-610 $128 \mathrm{~nm})$, and red $(610-700 \mathrm{~nm})$ light.

\section{Linear models}


131 The linear models (DS $\mathrm{L}_{\mathrm{d}}, \mathrm{L}_{\mathrm{f}}, \mathrm{O}_{\mathrm{d}}, \mathrm{O}_{\mathrm{f}}$ ) accurately fitted the data (table 1). The models 132 showed that individuals with bluer colouration and larger body size were more aggressive.

133 Model DS $\mathrm{L}_{\mathrm{f}}$ revealed that neophobic males were more aggressive (fig 1).

134

135 Table 1 The results of the linear models for lateral display duration (DS $\mathrm{L}_{\mathrm{d}}$ ) and frequency $136\left(\mathrm{DS} \mathrm{L}_{\mathrm{f}}\right)$ and opercular flare duration $\left(\mathrm{DS} \mathrm{O} \mathrm{O}_{\mathrm{d}}\right)$ and frequency $\left(\mathrm{DS} \mathrm{O}_{\mathrm{f}}\right)$

\begin{tabular}{|c|c|c|c|c|c|}
\hline Model & $R^{2}$ & & $F_{4,14}$ & & $P$ \\
\hline $\mathrm{DS} \mathrm{L}_{\mathrm{d}}$ & $46.5 \%$ & & 4.91 & & 0.012 \\
\hline$\overline{D S ~ L}$ & $58.0 \%$ & & 7.22 & & 0.002 \\
\hline $\mathrm{DS} \mathrm{O}_{\mathrm{d}}$ & $33.0 \%$ & & 3.21 , & & 0.046 \\
\hline $\mathrm{DS} \mathrm{O}_{\mathrm{f}}$ & $38.5 \%$ & & 3.81 & & 0.027 \\
\hline \multicolumn{6}{|l|}{$\operatorname{DS} L_{d}$} \\
\hline \multicolumn{2}{|l|}{ Variable } & \multicolumn{2}{|l|}{ Slope } & Std. error & $P$ value \\
\hline \multicolumn{2}{|l|}{ Mass } & \multicolumn{2}{|l|}{-15.26} & 45.83 & 0.74 \\
\hline \multicolumn{2}{|l|}{ Fin colour } & \multicolumn{2}{|l|}{-0.72} & 0.30 & 0.03 \\
\hline \multicolumn{2}{|l|}{ Body colour } & \multicolumn{2}{|l|}{-0.51} & 0.37 & 0.19 \\
\hline \multicolumn{2}{|l|}{ Neophobia } & \multicolumn{2}{|l|}{0.03} & 0.03 & 0.35 \\
\hline \multicolumn{6}{|l|}{$\operatorname{DS~L}_{\mathrm{f}}$} \\
\hline \multicolumn{2}{|l|}{ Variable } & \multicolumn{2}{|l|}{ Slope } & Std. error & $P$ value \\
\hline \multicolumn{2}{|l|}{ Mass } & \multicolumn{2}{|l|}{103.60} & 42.71 & 0.03 \\
\hline \multicolumn{2}{|l|}{ Fin colour } & \multicolumn{2}{|l|}{-0.88} & 0.28 & 0.01 \\
\hline \multicolumn{2}{|l|}{ Body colour } & \multicolumn{2}{|l|}{-0.34} & 0.35 & 0.34 \\
\hline \multicolumn{2}{|l|}{ Neophobia } & \multicolumn{2}{|l|}{-0.07} & 0.032 & 0.04 \\
\hline $\mathrm{DS} \mathrm{O}_{\mathrm{d}}$ & & & & & \\
\hline Variable & & Slope & & Std. error & $P$ value \\
\hline Mass & & 156.39 & & 59.77 & 0.02 \\
\hline Fin colour & & -0.66 & & 0.39 & 0.12 \\
\hline Body colour & & 0.26 & & 0.48 & 0.60 \\
\hline Neophobia & & -0.04 & & 0.05 & 0.38 \\
\hline DS O & & & & & \\
\hline Variable & & Slope & & Std. error & $P$ value \\
\hline Mass & & 171.78 & & 58.37 & 0.01 \\
\hline Fin colour & & -0.57 & & 0.38 & 0.16 \\
\hline Body colour & & 0.19 & & 0.47 & 0.69 \\
\hline Neophobia & & -0.04 & & 0.04 & 0.34 \\
\hline
\end{tabular}


a)

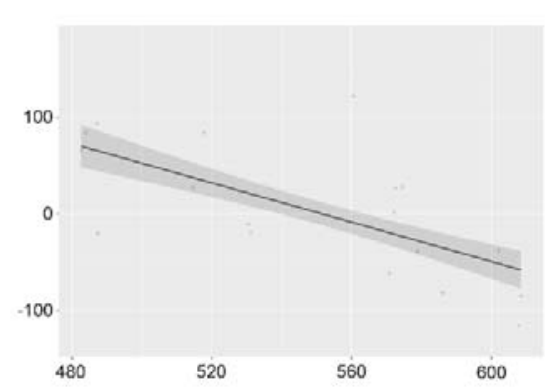

c)

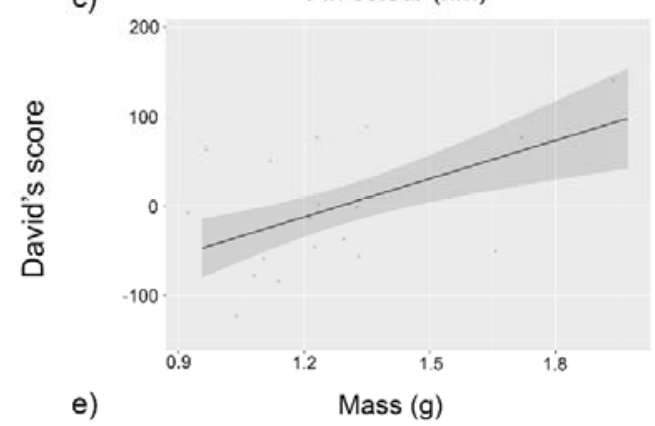

e)

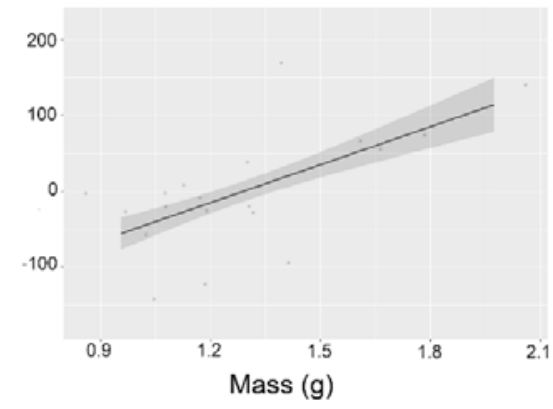

b) 200

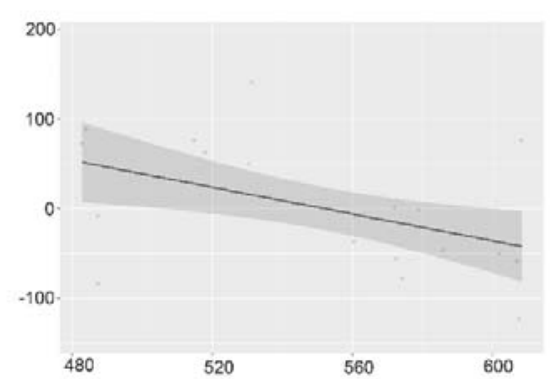

d)

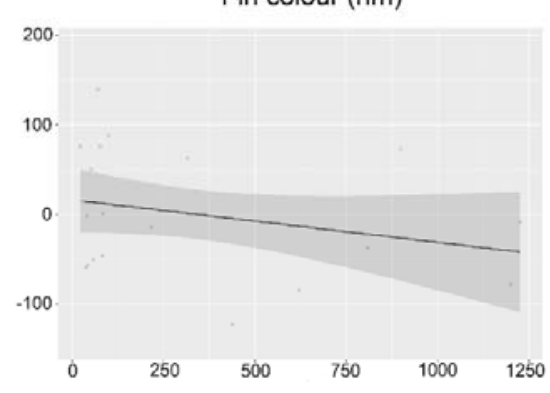

f)

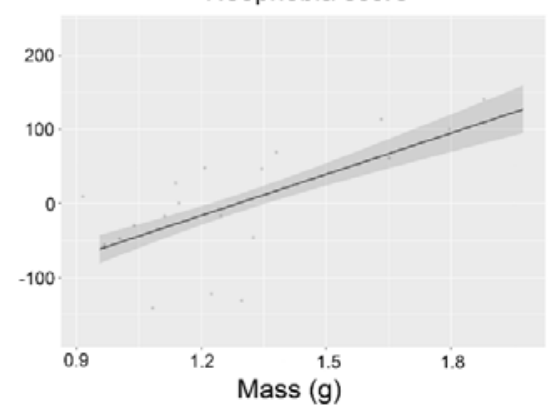

Fig. 1 Linear models using David's score found significant relationships between a lateral

140 display duration and fin colour $(P=0.03$, slope: -0.717$)$, b lateral display frequency and fin

141 colour $(P=0.007$, slope: -0.876$)$, c lateral display frequency and mass $(P=0.03$, slope: 104$)$

142 d lateral display frequency and neophobia $(P=0.04$, slope: -0.714$)$, e opercular flare duration

143 and body mass $(P=0.02$, slope: 156$), \mathbf{f}$ opercular flare frequency and mass $(P=0.01$, slope:

144 172). Confidence intervals are shown in grey.

\section{DISCUSSION}

147 Mass

148 Larger and heavier males tend to be stronger and more aggressive in many species, 149 leading to dominance (Arnott and Elwood 2009; Portugal et al. 2017b). The present study 150 showed that body mass is a predictor of aggression in male B. splendens. Mass may also be 151 indicative of fish with a larger labyrinth organ, which could impact opercular flare duration. 152 Opercular flaring concurrently inhibits aquatic respiration for the period that the opercular are 
153 raised (Abrahams et al. 2005). As displays between male B. splendens are highly intensive 154 and energetically demanding, the increased oxygen requirement (Castro et al. 2006) is met 155 solely by an increase in air-breathing at the surface (Alton et al. 2013). Body mass positively 156 correlates to oxygen uptake per breath (Alton et al. 2013), thus heavier males can afford to 157 perform longer and more frequent opercular flares (Forsatkar et al. 2016).

\section{Colour} males being most aggressive. Simpson (1968) also demonstrated that blue males displayed more readily and attacked more frequently than different coloured males when shown a mirror or puppet. Since fin flaring is a common behaviour during displays, it is likely that fin colour plays a significant role. Lateral displays are highly visual and males typically display near their opponent (Simpson 1968). Subsequently, aggressive males with a greater fighting ability can risk remaining in close proximity to their opponent.

Like some domestic variations, wild type males have blue fins (Simpson 1968). For wild B. splendens, their habitat is resource depleted, hypoxic, and murky (Graham 1997). In these conditions, vision may be limited to a short distance, reducing the effectiveness of visual cues. However, since blue light travels farther underwater (Day 2013), blue signals will be able to reach more opponents and make the colour appear more vibrant. The authors chose not to measure fin length, along with fin clour, as it has previously been shown not to alter aggression in B. splendens (Allen and Nicoletto 1997). performed more lateral displays than less neophobic individuals. Therefore, neophobic males may adopt a less costly aggressive behaviour to conserve energy and outlast aggressive opponents.

To reduce winner-loser effects altering the outcome and response of males several 182 precautions were put in place. Males were kept in isolation prior to and between encounters 183 to reduce potential effects on the response in following encounters. No individual was tested 184 more than once a day and encounters were randomised to reduce consecutive encounters 185 between the same pairs and habituation. Males were not tested on weekends to provide at 186 least a $60 \mathrm{~h}$ rest period in social isolation. Additionally, there was a 3-day rest period between 
each experiment type (aggression, boldness and neophobia) to reduce the studies impacting each other.

In conclusion, analysis of B. splendens behavioural and morphological traits revealed several predictors of aggression. Blue-finned males were the most aggressive individuals, performing longer lateral displays, more frequently, while red-finned males were the least aggressive. Additionally, heavier males initiated more opercular and lateral displays, in addition to longer opercular flares. Finally, neophobic individuals were more aggressive, performing more lateral displays. As male B. splendens vary in aggression (Simpson 1968), males may adopt different fighting strategies, with some males performing more opercular flares and others adopting a less costly method of fin flaring. Males may have to choose between ending a conflict quickly by escalating to more costly behaviours, such as opercular flaring, or trying to outlast their opponent by conserving energy using less costly behaviours, like fin flaring.

\section{Conflicts of interest}

The authors declare that they have no conflict of interest.

\section{Ethical approval}

All applicable international, national, and/or institutional guidelines for the care and

\section{ACKNOWLEDGEMENTS}

We are grateful to N. Morley and Z. Hale for feeding the fish, M. Tate for his help with observations and The Center for Behavioral Neuroscience for Stopwatch+. This research did not receive any funding from agencies in the public, commercial, or not-for-profit sectors.

\section{REFERENCES}

Abrahams MV, Robb TL, Hare JF (2005) Effect of hypoxia on opercular displays: evidence

for an honest signal? Anim Behav 70:427-432.
https://doi.org/10.1016/j.anbehav.2004.12.007 
217 Allen, J. M. \& Nicoletto, P. F. (1997). Response of Betta splendens to computer animations

218 of males with fins of different length. Copeia, 1, 195-199. Doi: 10.2307/1447858

219 Alton LA, Portugal SJ, White CR (2013) Balancing the competing requirements of air220 breathing and display behaviour during male-male interactions in Siamese fighting fish Betta splendens. Comp Biochem Physiol A Mol Integr Physiol 164:363-367. https://doi.org/10.1016/j.cbpa.2012.11.012

Arnott G, Elwood RW (2009) Assessment of fighting ability in animal contests. Anim Behav 77:991-1004. https://doi.org/10.1016/j.anbehav.2009.02.010

Castro N, Ros AFH, Becker K, Oliveira RF (2006) Metabolic costs of aggressive behaviour in the Siamese fighting fish, Betta splendens. Aggress Behav 32:474-480. https://doi.org/10.1002/ab.20147

Day T (2013) Ecosystems: Oceans. Routledge, New York, pp 44-61

Forsatkar MN, Nematollahi MA, Brown C (2016) Male Siamese fighting fish use gill flaring as the first display towards territorial intruders. $J$ Ethol 35:51-59. https://doi.org/10.1007/s10164-016-0489-1

Gammell MP, de Vries H, Jennings DJ, Carlin CM, Hayden TJ (2003) David's score: a more appropriate dominance ranking method than Clutton-Brock et al.'s index. Anim Behav 66:601-605. https://doi.org/10.1006/anbe.2003.2226

Graham JB (1997) Air-Breathing Fishes: Evolution, Diversity, and Adaptation. Academic Press, San Diego.

Hebert OL, Lavin LE, Marks JM, Dzieweczynski TL (2014) The effects of $17 \alpha-$ ethinyloestradiol on boldness and its relationship to decision making in male Siamese fighting fish. Anim Behav 87:203-212. https://doi.org/10.1016/j.anbehav.2013.10.032

Jaroensutasinee M, Jaroensutasinee K (2001) Sexual size dimorphism and male contest in wild Siamese fighting fish. J Fish Biol 59:1614-1621. https://doi.org/10.1111/j.10958649.2001.tb00225.x

Parker GA (1974) Assessment strategy and the evolution of fighting behaviour. $J$ Theor Biol 47:223-243. https://doi.org/10.1016/0022-5193(74)90111-8 dominance rank in birds. Ibis. 159: 456-462. 
250 Simpson MJA (1968) The display of the Siamese fighting fish, Betta splendens. Anim Behav

251 Monogr 1:1-71. https://doi.org/10.1016/S0066-1856(68)80001-9

252 Tate M, McGoran RE, White CR, Portugal SJ (2017) Life in a bubble: the role of the 253 labyrinth organ in determining territory, mating and aggressive behaviours in anabantoids. J Fish Biol 91:723-749. https://doi.org/10.1111/jfb.13357 